\title{
Prevalence and Impact of SDHI Fungicide Resistance in Alternaria solani
}

N. C. Gudmestad and S. Arabiat, Department of Plant Pathology, North Dakota State University, Fargo, ND 58108; J. S. Miller, Miller Research, 426 East 200 North, Rupert, ID 83350; and J. S. Pasche, Department of Plant Pathology, North Dakota State University, Fargo, ND 58108

Abstract

Gudmestad, N. C., Arabiat, S., Miller, J. S., and Pasche, J. S. 2013. Prevalence and impact of SDHI fungicide resistance in Alternaria solani. Plant \begin{abstract}
Dis. 97:952-960.
Early blight, caused by Alternaria solani, is an important chronic foliar disease of potato (Solanum tuberosum) present every growing season in the Midwestern United States. Most currently grown potato cultivars lack resistance to early blight; therefore, foliar fungicides are relied upon for disease management. Foliar fungicides with high efficacy against the pathogen, such as boscalid, frequently are used under high disease pressure situations, such as potatoes grown under overhead irrigation. Boscalid is a member of the succinate dehydrogenase inhibiting (SDHI) fungicide group and was registered for use on potato in 2005. Baseline sensitivity of $A$. solani to the SDHI fungicides boscalid, penthiopyrad, and fluopyram using a spore germination assay demonstrated similar intrinsic activity against $A$. solani with mean $\mathrm{EC}_{50}$ values of $0.33,0.38$, and $0.31 \mu \mathrm{g} / \mathrm{ml}$, respectively. However, isolates varied in their sensitivity to each of these fungicides, resulting in very low correlations $(r)$ among isolate sensitivity to each fungicide. Resistance to boscalid in A. solani was detected in the states of North Dakota, Minnesota, Nebraska, Texas, Idaho, Wisconsin, and Florida from early blight samples collected in 2010 and 2011. Two phenotypes of boscalid resistance were detected. Approximately $80 \%$ of all $A$.
\end{abstract}

solani assayed were found to have some level of resistance to boscalid with about 5 and $75 \%$ of the population moderately resistant (5 to 20 $\mu \mathrm{g} / \mathrm{ml})$ and highly resistant $(>20 \mu \mathrm{g} / \mathrm{ml})$, respectively, to the fungicide. Nearly $99 \%$ of all boscalid resistant isolates possessed the F129L mutation in the cytrochrome $\mathrm{b}$ gene, indicating that an A. solani population with dual fungicide resistance predominates in the states surveyed. However, A. solani isolates resistant to boscalid remained sensitive to fluopyram, and a large proportion of moderately resistant and resistant isolates were sensitive to penthiopyrad. Disease control data from in vivo trials demonstrated a significant loss of fungicide efficacy when boscalid and fluxapyroxad were used to control moderately and highly resistant isolates of $A$. solani relative to the control these fungicides provided wild-type isolates. Fluopyram, however, controlled boscalid resistant isolates as well as it controlled wild-type isolates of A. solani. These data will assist potato growers in regions where boscalid resistance is prevalent by assisting them in avoiding fungicides that do not effectively control early blight and in selecting SDHI fungicide molecules that remain efficacious.
Early blight of potato (Solanum tuberosum), caused by Alternaria solani Sorauer, is a chronic foliar disease of potato present every growing season, particularly in the midwestern portion of the United States (18). This disease is characterized by relatively small, discrete lesions with a concentric ring pattern (9). Early blight lesions tend to be evident initially on the older leaves as they senesce, eventually spreading to other foliage in the plant canopy under conditions conducive for disease development (9). Periods of free moisture from rain, dew, or overhead irrigation are required for spore germination and infection, and temperatures ranging from 5 to $30^{\circ} \mathrm{C}$ favor pathogen sporulation and disease development. Most currently grown potato cultivars are susceptible to early blight to varying degrees, thus, foliar fungicides are frequently used to manage the disease.

A number of foliar fungicides can be used to manage early blight in potato. Mancozeb and chlorothalonil are perhaps the most frequently used protectant fungicides for early blight management (10) but provide insufficient control under high disease pressure (18). Quinone outside inhibiting (QoI) fungicides were used successfully after their introduction in 1999, and provided a very high level of disease control $(18,22)$. Unfortunately, QoI resistance due to the F129L mutation in the cytochrome b gene was detected first in North Dakota and Nebraska in $2001(19,20)$ and was prevalent throughout much of the United States by 2006 (18). The F129L

Corresponding author: N. C. Gudmestad,

E-mail: neil.gudmestad@ndsu.edu

Accepted for publication 29 January 2013.

http://dx.doi.org/10.1094/PDIS-12-12-1176-RE

(c) 2013 The American Phytopathological Society mutation conveys a moderate level of resistance to QoI fungicides such as azoxystrobin and pyraclostrobin. The reduced efficacy of these two fungicides to levels of disease control provided by mancozeb and chlorothalonil (18) makes them less attractive for early blight disease management due to their increased cost compared to standard protectants. Boscalid (Endura) was registered in the United States for use on potato in 2005 and proved to be an excellent fungicide for early blight disease management $(18,19)$. As a result, throughout much of the potato growing regions of the United States where early blight is an important foliar disease, boscalid replaced the QoI fungicides in the foliar fungicide program.

Boscalid belongs to a class of fungicide referred to as succinate dehydrogenase inhibitors (SDHI). The primary target of SDHI fungicides is in the complex II electron transport system known as the succinate dehydrogenase (SDH) complex or the succinate:ubiquinone oxidoreductase respiratory chain (3). Molecules belonging to this class of fungicide bind to the ubiquinone-binding site of the mitochondrial complex II, thereby inhibiting fungal respiration. Despite having a similar biological mode of action, SDHI fungicides show no cross-resistance to QoI fungicides, which inhibit fungal respiration at mitochondrial complex III. This makes them excellent candidates for alternating with, or mixing with, QoI fungicides to manage fungicide resistance development while also providing superior disease control (21). Unfortunately, resistance to boscalid has developed quite readily and has been reported in A. alternata of pistachio (2-6), Botrytis cinerea in several crops $(8,12,17,25)$, Corynespora cassiicola of cucumber $(11,14,15)$, Didymella bryoniae of cucurbits (7), Monilinia fructicola of peach (1), Podosphaera xanthii of cucumber $(11,16)$, and A. solani of potato (24). Boscalid resistance in A. solani was first detected in 2009 and 2010 in Idaho with 15 and $62 \%$ of the isolates found to be insensitive to the fungicide (24). However, nothing is 
known about the prevalence of boscalid resistance in A. solani elsewhere.

The objectives of the research reported here were to (i) determine the prevalence and distribution of boscalid resistance in North Dakota, Minnesota, Nebraska, Idaho, and Texas; (ii) determine the impact of boscalid resistance on early blight disease control; and (iii) determine what impact boscalid resistance has on the fungicide sensitivity and disease control of $A$. solani by other SDHI fungicides such as penthiopyrad, fluxapyroxad, and fluopyram.

\section{Materials and Methods}

A. solani isolate collection and storage. Infected leaf samples were submitted to our laboratory during the 2010 and 2011 growing seasons from various potato production regions across the United States, including North Dakota, Minnesota, Nebraska, Michigan, Wisconsin, Idaho, Colorado, and Texas (Table 1). A. solani isolates were obtained by transferring a small portion of plant tissue from the margin of early blight lesions directly to solid

Table 1. Origin and collection year for Alternaria solani isolates used in vitro spore germination and in vivo greenhouse fungicide sensitivity assays

\begin{tabular}{llc}
\hline Year & State of origin & No. of isolates \\
\hline $1998^{z}$ & North Dakota & 1 \\
& Minnesota & 5 \\
& Idaho & 2 \\
& Nebraska & 13 \\
& Texas & 1 \\
& South Dakota & 1 \\
$2001^{z}$ & Wisconsin & 1 \\
& North Dakota & 11 \\
2010 & Minnesota & 5 \\
& Nebraska & 17 \\
& North Dakota & 15 \\
2011 & Idaho & 27 \\
& Nebraska & 12 \\
& North Dakota & 11 \\
& Minnesota & 29 \\
& Idaho & 16 \\
& Nebraska & 31 \\
& Texas & 15 \\
& Wisconsin & 3 \\
& Colorado & 4 \\
& Michinigan & 2 \\
\hline
\end{tabular}

${ }^{\mathrm{z}}$ Isolates collected in 1998 and 2001 had no known exposure to succinate dehydrogenase inhibiting (SDHI) fungicides and therefore are considered baseline.
$1.5 \%$ agar media and incubating at room temperature $\left(22 \pm 2^{\circ} \mathrm{C}\right)$ for 3 to 4 days until conidia were produced. A single conidium was transferred to a solid clarified V8 media (CV8) (Campbell's V8 juice, $100 \mathrm{ml}$; $\mathrm{CaCO}_{3}, 1.5 \mathrm{~g}$; agar, $15 \mathrm{~g}$; and distilled water, 900 $\mathrm{ml}$ ) amended with $50 \mathrm{mg} / \mathrm{ml}$ ampicillin as previously described (10). Cultures were incubated under continuous fluorescent light for 7 to 10 days, examined for the presence of conidia with the aid of a stereomicroscope, and subsequently transferred to long-term storage (20).

The baseline sensitivity of $A$. solani isolates to penthiopyrad and fluopyram was compared to the baseline sensitivity of this fungus to boscalid. A. solani isolates with no exposure to SDHI fungicides, and previously evaluated for sensitivity to boscalid, were obtained from long-term storage (19). These 57 baseline isolates were collected in 1998 and 2001 and have no known exposure to SDHI fungicides registered in 2005 . Additionally, A. solani isolates collected in 2010 (54 isolates) and 2011 (111 isolates) were evaluated for in vitro sensitivity to three SDHI fungicides (Table 1). Isolates collected in 2010 were primarily from potato fields in which growers had expressed concern about a lack of early blight disease control after having used boscalid in their foliar fungicide regime. Isolates from 2011 were arbitrarily selected by collecting 15 to 20 leaves per field from several potato production regions within each state. Isolations to recover the causal agent were as described above.

In vitro sensitivity to SDHI fungicides. In vitro SDHI sensitivity was evaluated via conidial germination assays conducted as described previously (19) using 7- to 14-day-old cultures of $A$. solani maintained under continuous fluorescent light at $22 \pm 2{ }^{\circ} \mathrm{C}$. Briefly, a glass rod was used to free conidia from the surface of the CV8 media using sterile, distilled water under aseptic conditions. The conidial concentration of the suspension was determined using a hemocytometer, adjusted to $2 \times 10^{4}$ conidia/ml, and $150 \mu \mathrm{l}$ was added to the surface of the fungicide amended media. Media containing 2\% laboratory grade agar (A360-500 Fisher Scientific, Pittsburgh, PA) were amended with technical grade boscalid (99\% active ingredient [a.i.]; BASF Corporation, Research Triangle Park, NC), fluopyram (97.78\% a.i.; Bayer CropScience, Monheim am Rhein, Germany), and penthiopyrad (100\% a.i.; DuPont Crop Protection, Wilmington, DE) dissolved in acetone (approximately 10 $\mathrm{mg}$ of a fungicide per $\mathrm{ml}$ ) and diluted in deionized water to reach final concentrations of $0,0.01,0.1,1,10$, and $100 \mathrm{mg} / \mathrm{ml}$. The final concentration of acetone in the media was $0.1 \%$ by volume. The highest concentration was not required for fluopyram evaluations since no isolates were identified with resistance to this fungicide. Salicylhydroxamic acid (SHAM), previously determined to not inhibit conidial germination (20), was dissolved in methanol and

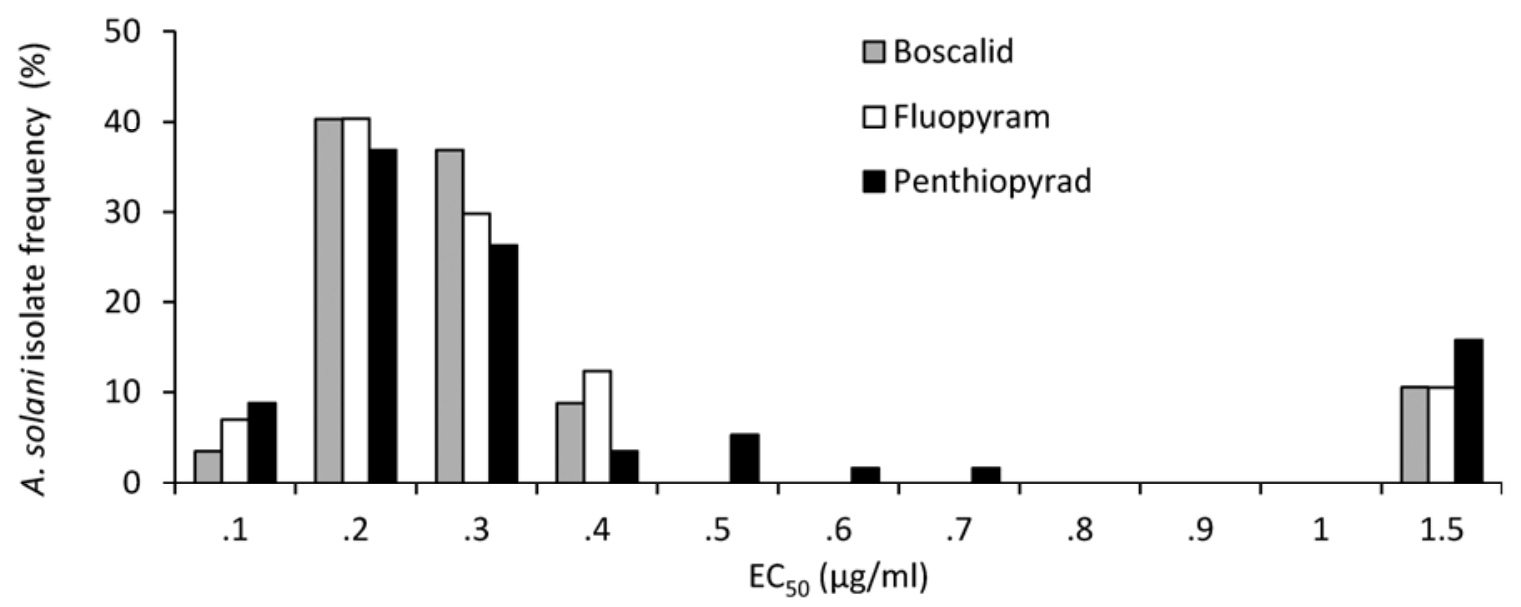

Fig. 1. Frequency distribution of sensitivity of 57 baseline Alternaria solani isolates to the succinate dehydrogenase inhibiting (SDHI) fungicides boscalid, fluopyram, and penthiopyrad using in vitro methods to determine the effective concentration which inhibits spore germination by $50 \%$ compared to the nonamended control $\left(\mathrm{EC}_{50} \mu \mathrm{g} / \mathrm{ml}\right)$.

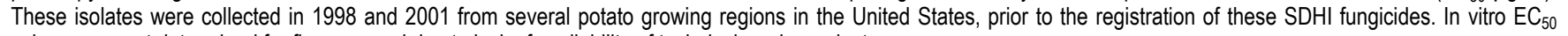
values were not determined for fluxapyroxad due to lack of availability of technical grade product. 
added to the media to reach a final concentration of $100 \mathrm{mg} / \mathrm{ml}$ to be consistent with previous boscalid studies (19). A. solani isolates with $\mathrm{EC}_{50}$ values greater than $100 \mu \mathrm{g} / \mathrm{ml}$ of boscalid were evaluated further at fungicide concentrations of $0,0.01,0.1,1,10,100,250$, and $500 \mu \mathrm{g} / \mathrm{ml}$. Due to the low solubility of technical grade fungicides in water and acetone, $50 \mathrm{mg} / \mathrm{ml}$ stock solutions of formulated products of boscalid (70\% a.i.; Endura, BASF Corporation) and
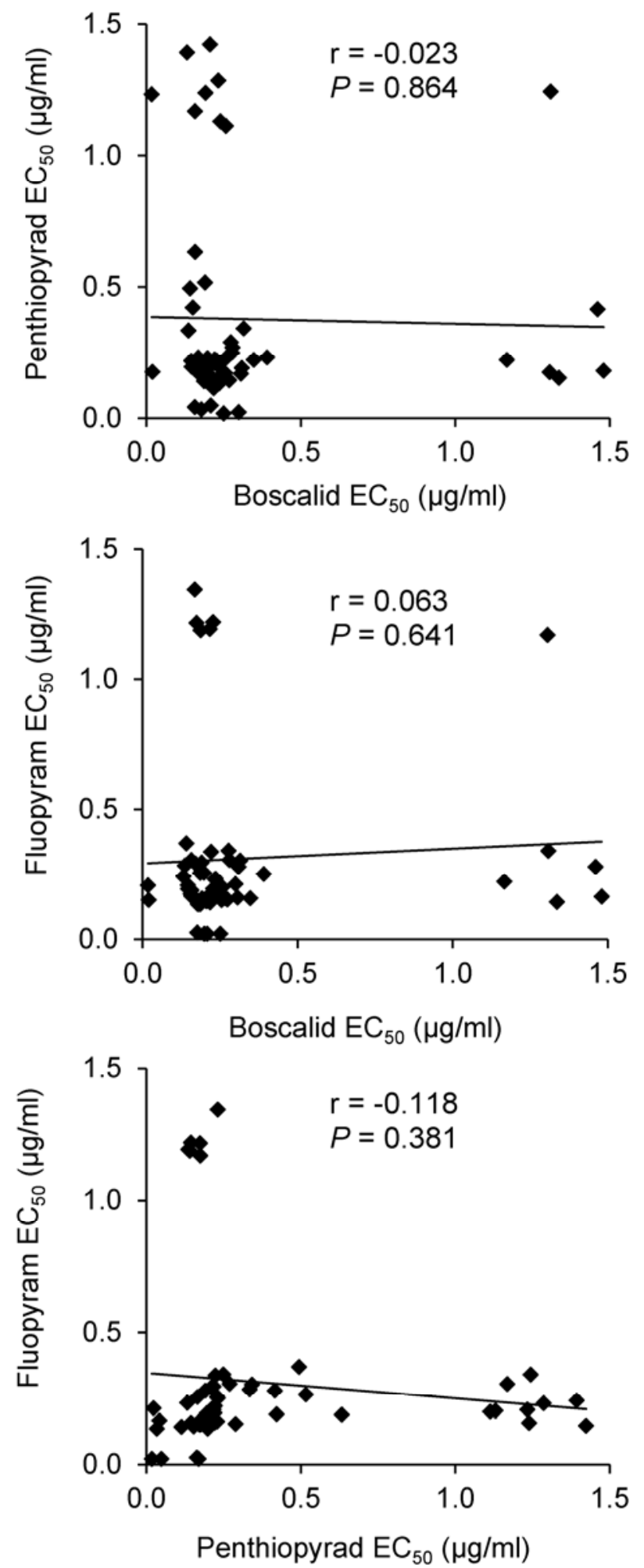

Fig. 2. Pearson's correlation illustrating in vitro sensitivities to succinate dehydrogenase inhibiting (SDHI) fungicides boscalid, fluopyram, and penthiopyrad among 57 Alternaria solani isolates collected in 1998 and 2001, having no exposure to this class of fungicides. In vitro $\mathrm{EC}_{50}$ values were not determined for fluxapyroxad due to lack of availability of technical grade product. penthiopyrad (20.6\% a.i.; Vertisan, DuPont Crop Protection) were used to prepare fungicide amended media at concentrations greater than $100 \mu \mathrm{g} / \mathrm{ml}$.

In all in vitro fungicide sensitivity assays, petri plates were incubated at $21^{\circ} \mathrm{C}$ under continuous light for $4 \mathrm{~h}$ prior to evaluation for conidial germination $(19,20)$. Following incubation, 50 conid$\mathrm{ia} /$ plate were examined for the development of one germ tube at least as long as the conidium, or multiple germ tubes developing from one conidium, using a microscope at $\times 100$ magnification $(19,20)$. All experiments were performed twice with two replicates for each fungicide concentration. The $165 \mathrm{~A}$. solani isolates tested for SDHI fungicide sensitivity were tested in 62 trials, with 6 to 24 isolates included in each trial. Control isolates 13-1, a wild-type $A$. solani isolate, and 526.3, QoI resistant, were included in each trial as an internal control. Each A. solani isolate collected in 2010 and 2011 was evaluated a minimum of three times to determine its sensitivity to each SDHI fungicide.

To calculate $\mathrm{EC}_{50}$ values, the percent reduction in germination relative to the non-fungicide-amended control was calculated, and regressed against the $\log _{10}$ fungicide concentration. The concentration that reduced germination by half, compared to media not amended with fungicide, was extrapolated from the $50 \%$ intercept $\left(\mathrm{EC}_{50}\right.$ value). A. solani isolates were placed into three categories based on in vitro boscalid sensitivity. Isolates with mean $\mathrm{EC}_{50}$ values lower than $5 \mu \mathrm{g} / \mathrm{ml}$ were considered sensitive to the fungicide, while isolates with $\mathrm{EC}_{50}$ values ranging from 5 to $20 \mu \mathrm{g} / \mathrm{ml}$, and greater than $20 \mu \mathrm{g} / \mathrm{ml}$, were considered moderately and highly resistant, respectively. Sensitivity to QoI fungicides was determined by the melting temperature analysis method using real-time polymerase chain reaction (PCR) for detection of the F129L mutation (19) for each A. solani isolate evaluated for SDHI sensitivity in vitro.

Effect of boscalid resistance on early blight disease control using SDHI fungicides. The impact of boscalid resistance in $A$. solani on early blight control provided by four SDHI fungicides was evaluated under greenhouse conditions as previously described $(19,20)$. This was done by inoculating isolates of the early blight fungus onto plants treated with different doses of each fungicide. Five A. solani isolates were selected for in vivo disease control evaluations based on in vitro boscalid sensitivity. Two wildtype/boscalid sensitive $\left(\mathrm{EC}_{50} 0.28\right.$ to $0.32 \mu \mathrm{g} / \mathrm{ml}$ ), one moderately resistant $\left(\mathrm{EC}_{50} 5.9 \mu \mathrm{g} / \mathrm{ml}\right)$, and two highly resistant isolates $\left(\mathrm{EC}_{50}\right.$ 150 to $>500 \mu \mathrm{g} / \mathrm{ml}$ ) were used. Isolates maintained on solid CV8 media for 7 to 14 days under continuous fluorescent light at $22 \pm$ $2{ }^{\circ} \mathrm{C}$ were used to prepare a suspension of $2 \times 10^{5}$ conidia $/ \mathrm{ml}$ sterile distilled water. Tomato plants, cv. Orange Pixie VFT Hybrid (Tomato Growers Supply Company, Fort Myers, FL), were grown in the greenhouse under natural light and ambient temperatures in 10 $\mathrm{cm}^{3}$ pots containing Sunshine Mix LC1 (73 to 83\% Canadian sphagnum peat moss, perlite, and dolomite lime) until the first three leaves were fully expanded and plants were approximately 20 $\mathrm{cm}$ in height. The dose response curve was developed by using serial fungicide dilutions $(0,0.1,1,10$, and $100 \mu \mathrm{g} / \mathrm{ml})$ of four SDHI fungicides, boscalid (70.0\% a.i.; Endura), penthiopyrad (20.6\% a.i.; Vertisan), fluopyram (41.5\% a.i.; Luna, Bayer), and fluxapyroxad (30.0\% a.i.; Xemium, BASF), which were prepared from stock solutions as described above for formulated products. Fungicides were applied preventively using a Generation III Research Sprayer (Devries Manufacturing, Hollandale, MN) starting with the lowest concentration. The sprayer was rinsed thoroughly with distilled water between fungicides. Tomato plants were inoculated using $50 \mathrm{ml}$ of conidial suspension/plant $24 \mathrm{~h}$ postfungicide application. Inoculated plants were kept for $24 \mathrm{~h}$ at $22 \pm 2{ }^{\circ} \mathrm{C}$ in humid chambers (Phytotronic.inc; 1626D). High relative humidity was maintained by applying mist for $10 \mathrm{~s}$ out of every $2 \mathrm{~min}$. Plants subsequently were transferred to confinement chambers with four walls and open ceilings on greenhouse benches at $25 \pm$ $2{ }^{\circ} \mathrm{C}$ to minimize inter-isolate interference. Percent disease severity was assessed on three fully expanded true leaves on each of two plants/pot, one pot/replicate and three replicates (18 leaves/ 
treatment) at 6, 9, and 12 days postinoculation (DPI). The in vivo experiment was performed three times.

Statistical analyses. Correlation coefficients comparing in vitro fungicide $\mathrm{EC}_{50}$ values for both baseline and 2010-2011 A. solani isolates were determined using a Pearson correlation analyses $(\alpha=$ $0.05)$. In vivo disease control experiments were conducted using a split plot design with $A$. solani isolates as the main plot and fungicide concentration as the split plot. Disease severity was transformed to percent disease control using the formula (1 - (\% diseased tissue $/ \%$ diseased tissue in non-fungicide-control plants; 0 $\mu \mathrm{g} / \mathrm{ml} \times 100$ ). Levene's test for homogeneity of variance was performed to ensure that the two in vivo trials could be combined for further data analysis (13). A two-factor ANOVA was performed using isolate and fungicide as the main factors at each fungicide concentration. Because a significant interaction $(\alpha=0.05)$ was observed between the main effects of isolate and fungicide, further ANOVAs were performed to evaluate an isolate's response within each fungicide.

\section{Results}

Baseline in vitro sensitivity of $A$. solani to boscalid, penthiopyrad, and fluopyram. The intrinsic sensitivity of $A$. solani isolates to the SDHI fungicides boscalid, penthiopyrad, and fluopyram was very similar (Fig. 1). Patterns illustrated by the frequency distributions of the fungicides reflect these similarities. For each fungicide, $\mathrm{EC}_{50}$ values ranged from 0.017 to $1.48,0.018$ to 1.42 , and 0.021 to $1.34 \mu \mathrm{g} / \mathrm{ml}$ (Fig. 1) with mean $\mathrm{EC}_{50}$ values of 0.33 , 0.38 , and $0.31 \mu \mathrm{g} / \mathrm{ml}$ for boscalid, penthiopyrad, and fluopyram, respectively. However, the sensitivity of individual baseline $A$. solani isolates to each SDHI fungicide varied substantially, resulting in very low and non-significant correlation coefficients among fungicides (Fig. 2). This means that although the range of sensitivities and mean sensitivity of baseline $A$. solani populations to the three SDHI fungicides were very similar, an individual isolate may vary substantially in its sensitivity to each fungicide.

In vitro sensitivity of $A$. solani isolates collected in 2010 and 2011. A shift in sensitivity to boscalid was detected in $A$. solani isolates collected in 2010 and 2011 from Idaho, Minnesota, Nebraska, North Dakota, and Texas (Fig. 3). Additionally, resistance to boscalid also was detected in A. solani collected from single potato fields in Colorado, Wisconsin, and Florida (data not shown). Two phenotypes of boscalid resistance appear to exist among the isolates assayed. A moderate level of boscalid resistance exists in A. solani isolates with $\mathrm{EC}_{50}$ values ranging from 5 to $20 \mu \mathrm{g} / \mathrm{ml}$, representing a 15 - to 60 -fold loss in sensitivity to the fungicide, compared to the mean sensitivity of baseline isolates (Fig. 3). The second phenotype of boscalid resistance in A. solani is a high or very high level of resistance in isolates with $\mathrm{EC}_{50}$ values ranging from 40 to $>500 \mu \mathrm{g} / \mathrm{ml}$, representing a $>100$-fold loss in sensitivity. Interestingly, some isolates with moderate or high levels of resistance to boscalid remained sensitive to penthiopyrad while others were moderately resistant to both fungicides (Fig. 3). As a result, the correlation among $\mathrm{EC}_{50}$ values of penthiopyrad and boscalid for $A$. solani isolates collected in 2010 and 2011 was not statistically significant (Fig. 4A). However, all A. solani isolates with boscalid resistance collected in 2010 and 2011 remained sensitive to fluopyram (Fig. 3), although a few isolates were just outside the baseline. In fact, isolates resistant to boscalid tended to be more sensitive to fluopyram than boscalid sensitive isolates ( $r=$ $-0.169)$, resulting in a statistically significant inverse relationship (Fig. 4B). The relationship between penthiopyrad and fluopyram sensitivity in A. solani isolates collected in 2010 and 2011 was also highly significant (Fig. 4C).

Boscalid resistance in A. solani isolates was detected in each state studied (Fig. 5A). The frequency of isolates carrying high resistance to boscalid varied from $42 \%$ in Idaho to $87 \%$ in Texas, but was the dominate phenotype in every state surveyed. Interestingly, the frequency of isolates with a moderate level of boscalid resistance varied from zero in Minnesota to $23 \%$ of the population in Idaho (Fig. 5A). Across all five states surveyed, the frequency of boscalid resistant isolates, regardless of phenotype, was $75 \%$. All of the isolates assayed remained sensitive to fluopyram (Fig. 5B) and were also predominately sensitive to penthiopyrad (Fig. 5C). The frequency of $A$. solani isolates sensitive to penthiopyrad varied from $69 \%$ in North Dakota to $87 \%$ in Texas (Fig. 5C). The frequency of isolates with moderate levels of resistance to penthiopyrad was very consistent among states, ranging from 8 to $17 \%$. A. solani isolates highly resistant to penthiopyrad varied from $0 \%$ in Texas to $23 \%$ in North Dakota (Fig. 5C). The F129L mutation in the cytochrome $\mathrm{b}$ gene was detected in $98.5 \%$ of the A. solani isolates that had resistance to boscalid (data not shown).

Effect of boscalid resistance on early blight disease control. Significant differences among $A$. solani isolates were observed in disease control provided by boscalid at all levels of the fungicide (Table 2; Fig. 6A). A. solani isolates with high levels of resistance to boscalid (1179-11 and 1179-3) were not controlled by this fungicide at doses above $0.1 \mu \mathrm{g} / \mathrm{ml}$ compared to the level of control provided wild-type isolates. At $1 \mu \mathrm{g} / \mathrm{ml}$, highly resistant $A$. solani isolates were controlled significantly less than sensitive isolates (13-1 and 1178-W1), but not when compared to the moderately resistant isolate $(1178-\mathrm{E} 1)$. At 10 and $100 \mu \mathrm{g} / \mathrm{ml}$, highly resistant isolates were controlled at a significantly lower level than both sensitive and moderately resistant $A$. solani isolates. When the same group of isolates was tested for in vivo sensitivity to fluopy-

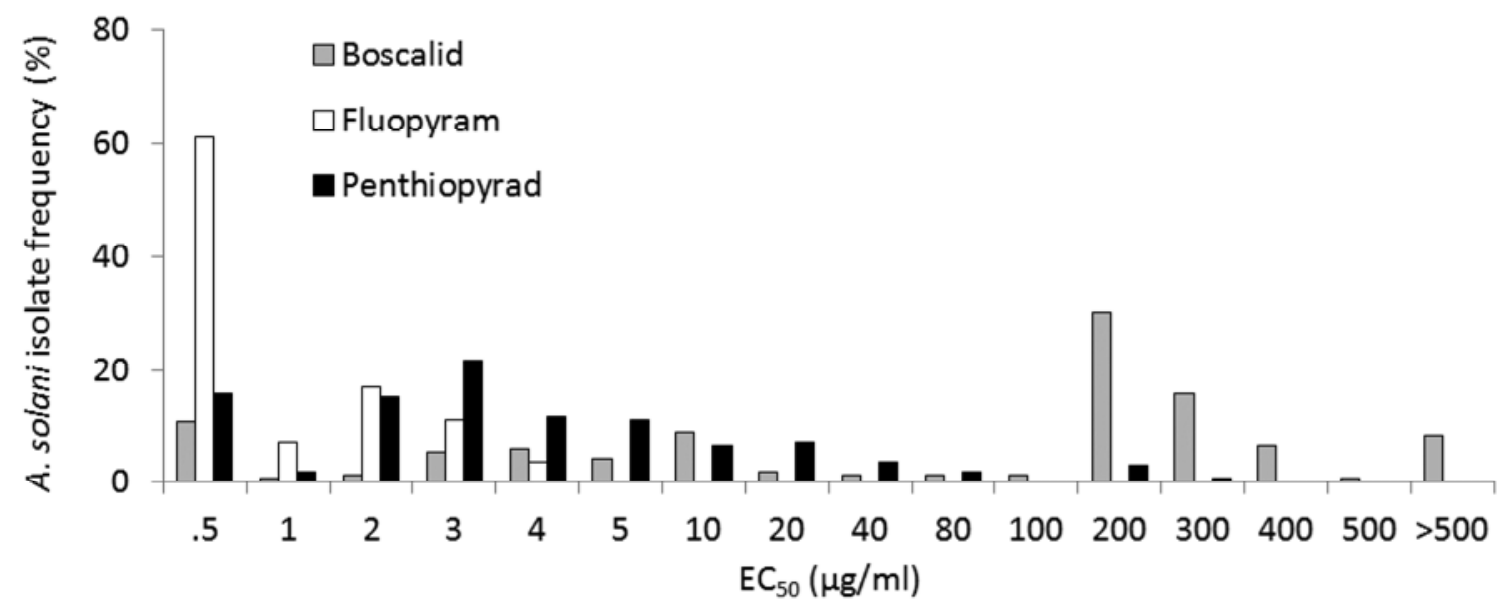

Fig. 3. Frequency distribution of sensitivity of Alternaria solani isolates to the succinate dehydrogenase inhibiting (SDHI) fungicides boscalid, fluopyram, and penthiopyrad using in vitro methods to determine the effective concentration which inhibits spore germination by $50 \%$ compared to the nonamended control $\left(\mathrm{EC}_{50} \mu \mathrm{gg} / \mathrm{ml}\right)$. Fifty-four and 111 isolates were evaluated in 2010 and 2011, respectively, from several potato growing regions in the United States. In vitro $\mathrm{EC}_{50}$ values were not determined for fluxapyroxad due to lack of availability of technical grade product. 
ram, significant differences in disease control were observed at 0.1 , 1 , and $10 \mu \mathrm{g} / \mathrm{ml}$ (Table 2; Fig. 6B). However, these differences were not as great, and could not be explained by in vitro fluopyram sensitivity, as was observed with boscalid. Penthiopyrad effectively controlled A. solani isolates with moderate levels of boscalid resistance, but did not effectively control isolates with high levels of boscalid resistance (Table 2; Fig. 6C). Additionally, some reduced
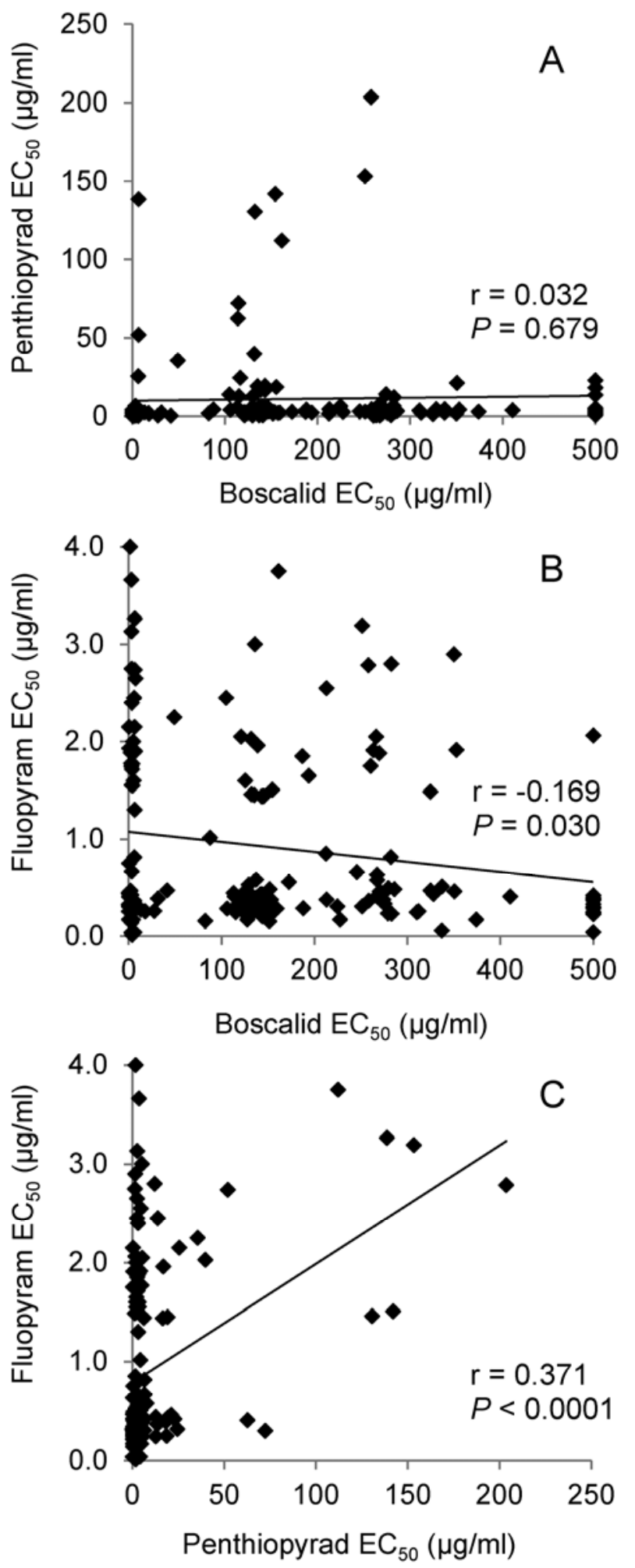

Fig. 4. Pearson's correlation illustrating in vitro senstivities to succinate dehydrogenase inhibiting (SDHI) fungicides boscalid, fluopyram, and penthiopyrad among 54 and 111 Alternaria solani isolates collected in 2010 and 2011, respectively. In vitro $\mathrm{EC}_{50}$ values were not determined for fluxapyroxad due to lack of availability of technical grade product. levels of control, although not always significant, were observed with one sensitive isolate, as was the case with fluopyram. The levels of control provided by fluxapyroxad nearly mirror those observed with penthiopyrad (Table 2; Fig. 6D). Both highly resistant isolates were controlled significantly less than one sensitive and moderately resistant isolate at all concentrations of the fungicide. The sensitive $A$. solani isolate, 13-1, also was controlled less than the other sensitive and moderately sensitive isolates, but not always significantly.

\section{Discussion}

Boscalid resistance first was detected in A. solani in field isolates collected in 2009 and 2010 from Idaho (24). In that report, 46 A. solani isolates were tested for sensitivity to boscalid, and these isolates were reported to be either completely resistant or completely sensitive to boscalid, although $\mathrm{EC}_{50}$ values for these isolates were not reported. In the studies reported here, it is apparent that resistance to boscalid in A. solani was also prevalent in North Dakota, Minnesota, Nebraska, and Texas in 2010 and 2011. Additionally, boscalid resistance also was detected in the $A$. solani isolates recovered from early blight infected potato leaves sent to our laboratory from single potato fields in Colorado, Wisconsin, and Florida. These studies also reconfirm that boscalid resistance is present in A. solani recovered from early blight infected leaves from Idaho. In contrast to the previous report of complete resistance to boscalid in A. solani (24), it is apparent from the studies presented here that there are two distinct phenotypes, or levels of boscalid resistance, in A. solani. Across all locations, and encompassing 165 isolates of A. solani, approximately $75 \%$ of all isolates exhibited some level of resistance to boscalid. Highly resistant phenotypes predominate, however, with these isolates possessing $\mathrm{EC}_{50}$ values $>100 \mu \mathrm{g} / \mathrm{ml}$. In most states, moderately resistant isolates with $\mathrm{EC}_{50}$ values between 5 and $20 \mu \mathrm{g} / \mathrm{ml}$ constituted $<10 \%$ of the $A$. solani population. Interestingly, A. solani isolates collected from Idaho were more uniformly distributed among the phenotypes with approximately 23 and $42 \%$ possessing moderate to high levels of resistance to boscalid, respectively. Differential levels of resistance to boscalid also have been reported in several other plant pathogenic fungi $(3,4,8,11,14-16,25)$, and are putatively due to mutations present in different gene subunits, usually sdhB, sdhC, and sdhD (3).

Our research group established the baseline sensitivity of $A$. solani to boscalid in a previous report (19). During those studies, we detected substantial variation in the sensitivity of $A$. solani isolates that had never been exposed to the fungicide, ranging from 0.16 to $2.7 \mu \mathrm{g} / \mathrm{ml}$, which represents a nearly 17 -fold difference in sensitivity from the most to least sensitive (19). The results of the current study are in agreement with those previously published but were repeated here to compare baseline sensitivity to SDHI fungicides registered on potato directly. During the development of a baseline sensitivity to penthiopyrad and fluopyram, two more recently developed SDHI fungicides, we used the identical A. solani isolates from our previous study and we repeated the boscalid baseline in order to bridge the two studies. Despite the fact that the distribution of $\mathrm{EC}_{50}$ values for SDHI fungicides boscalid, penthiopyrad, and fluopyram among baseline isolates were very similar, the correlations among them were very low, with $r$ ranging from 0.063 to -0.118 . Furthermore, the range in sensitivity of baseline A. solani isolates to the three SDHI fungicides studied remains a concern. In the baseline sensitivity established in the current study, there is a 64- to 87-fold difference in sensitivity from the most SDHI sensitive isolates to the least sensitive. Although it has been demonstrated previously that there are differential effects of mutations in the sdh subunits to boscalid and fluopyram $(3,7,11)$, to our knowledge this is the first report of a differential sensitivity and lack of correlation among baseline isolates of a fungal population to several SDHI fungicides. In contrast, it has been previously reported that a significant correlation existed in a baseline population of Didymella bryoniae and sensitivity to penthiopyrad and boscalid (23). It is unfortunate that we were unable to secure technical grade fluxapyroxad, as it would have been very informative 
to compare the sensitivity of a baseline A. solani population to this fungicide relative to the other SDHI fungicides studied, particularly boscalid.

It has been demonstrated in previous studies that there is a lack of cross-resistance between SDHI fungicides boscalid and fluopyram among isolates that have developed resistance to the former fungicide $(3,7,11)$. In contrast, there does appear to be cross-resistance between SDHI fungicides boscalid and penthiopyrad among isolates that have developed resistance to boscalid $(3,7,11,23)$. This suggests that plant pathogenic fungi that develop resistance to boscalid remain sensitive to fluopyram but not to penthiopyrad. In the studies reported here, boscalid resistant $A$. solani isolates also remained sensitive to fluopyram, clearly confirming a lack of cross-resistance between the two fungicides. However, in contrast to previous studies, it appears that there is also a lack of cross-resistance among some $A$. solani isolates when comparing the sensitivity of boscalid resistant isolates to penthiopyrad. Isolates with moderate levels of resistance to boscalid appear sensitive to penthiopyrad, but some isolates highly resistant to boscalid are also highly resistant to penthiopyrad. The lack of cross-resistance between boscalid and fluopyram in A. alternata has been attributed to the higher intrinsic activity of this molecule
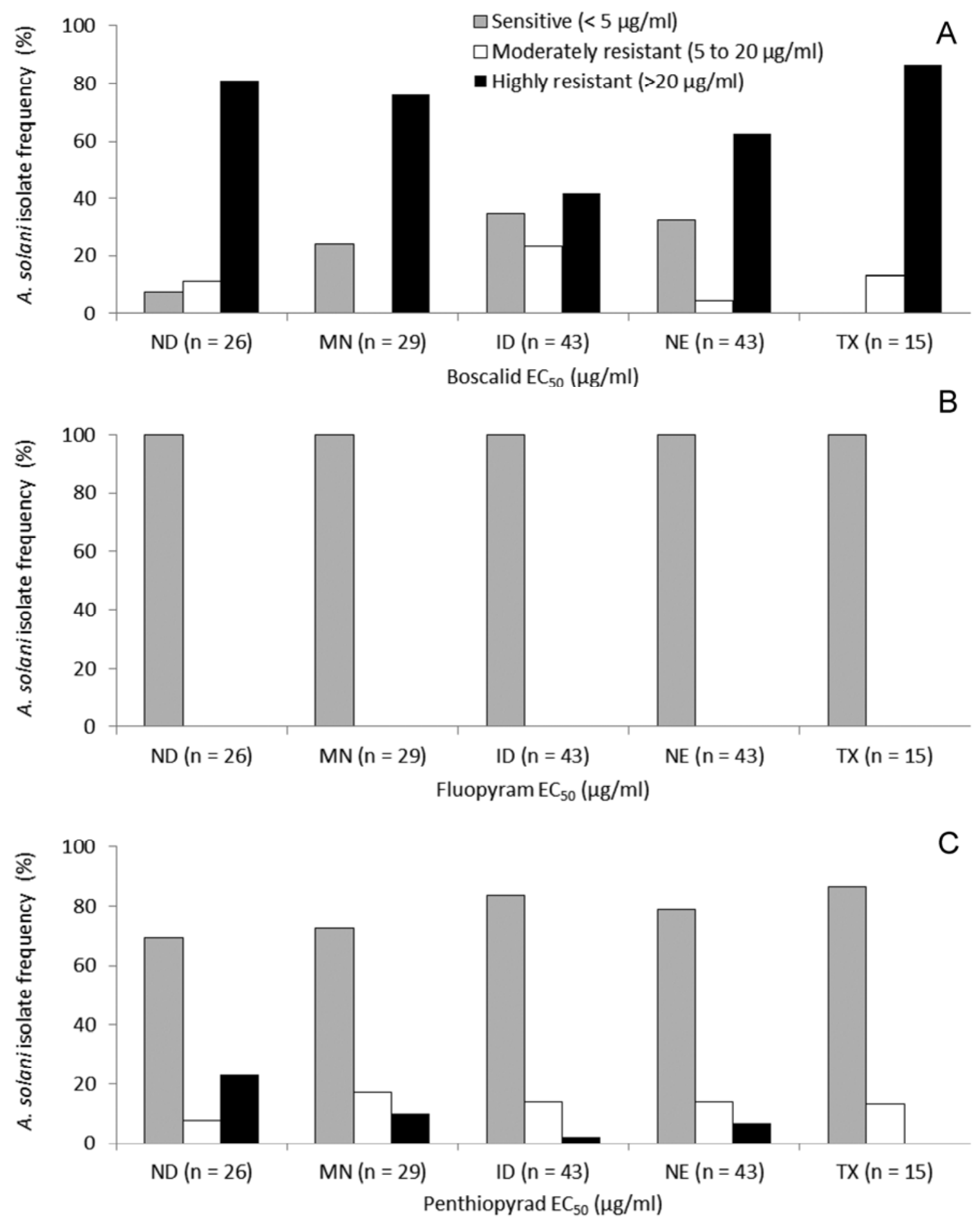

Fig. 5. Frequency distribution of sensitivity of Alternaria solani isolates to the succinate dehydrogenase inhibiting (SDHI) fungicides A, boscalid; B, fluopyram; and C, penthiopyrad using in vitro methods to determine the effective concentration which inhibits spore germination by $50 \%$ compared to the nonamended control $\left(\mathrm{EC}_{50} \mu \mathrm{\mu g} / \mathrm{ml}\right)$. Isolates were collected in 2010 and 2011 from several North Dakota (ND), Minnesota (MN), Idaho (ID), Nebraska (NE), and Texas (TX) fields. In vitro EC 50 values were not determined for fluxapyroxad due to lack of availability of technical grade product. 
compared to boscalid, although no evidence was provided to substantiate differences in intrinsic activity between these two SDHI fungicides in this fungus. In the current studies, it is clear that there are no differences in intrinsic activity of boscalid and fluopyram on a baseline population of $A$. solani relative to the range of sensitivities that exist in a baseline population. We believe that in $A$. solani it is more likely that fluopyram binds at a different site on the ironsulfur protein, or elsewhere in complex II (3), than does boscalid and, therefore, is unaffected by the same mutations. However, this will be the subject of future studies.

The presence of boscalid resistance in A. solani significantly reduced the level of disease control provided by that fungicide. Not surprisingly, the degree of disease control loss was consistent with the in vitro phenotype of the $A$. solani isolate. For example, isolates with moderate levels of in vitro boscalid resistance were controlled to a higher degree than isolates of $A$. solani with high levels of resistance to the fungicide. The level of disease control boscalid provided for moderately resistant isolates was very similar to that reported for QoI fungicides azoxystrobin and pyraclostrobin controlling A. solani isolates with the F129L mutation $(19,20)$. Under field conditions, the level of control azoxystrobin and pyraclostrobin provided isolates with the F129L mutation was not significantly different from the level of control provided by protectant fungicides such as mancozeb and chlorothalonil (18). We would expect similar results for boscalid in controlling moderately resistant isolates based on the in vivo data reported here. Isolates of
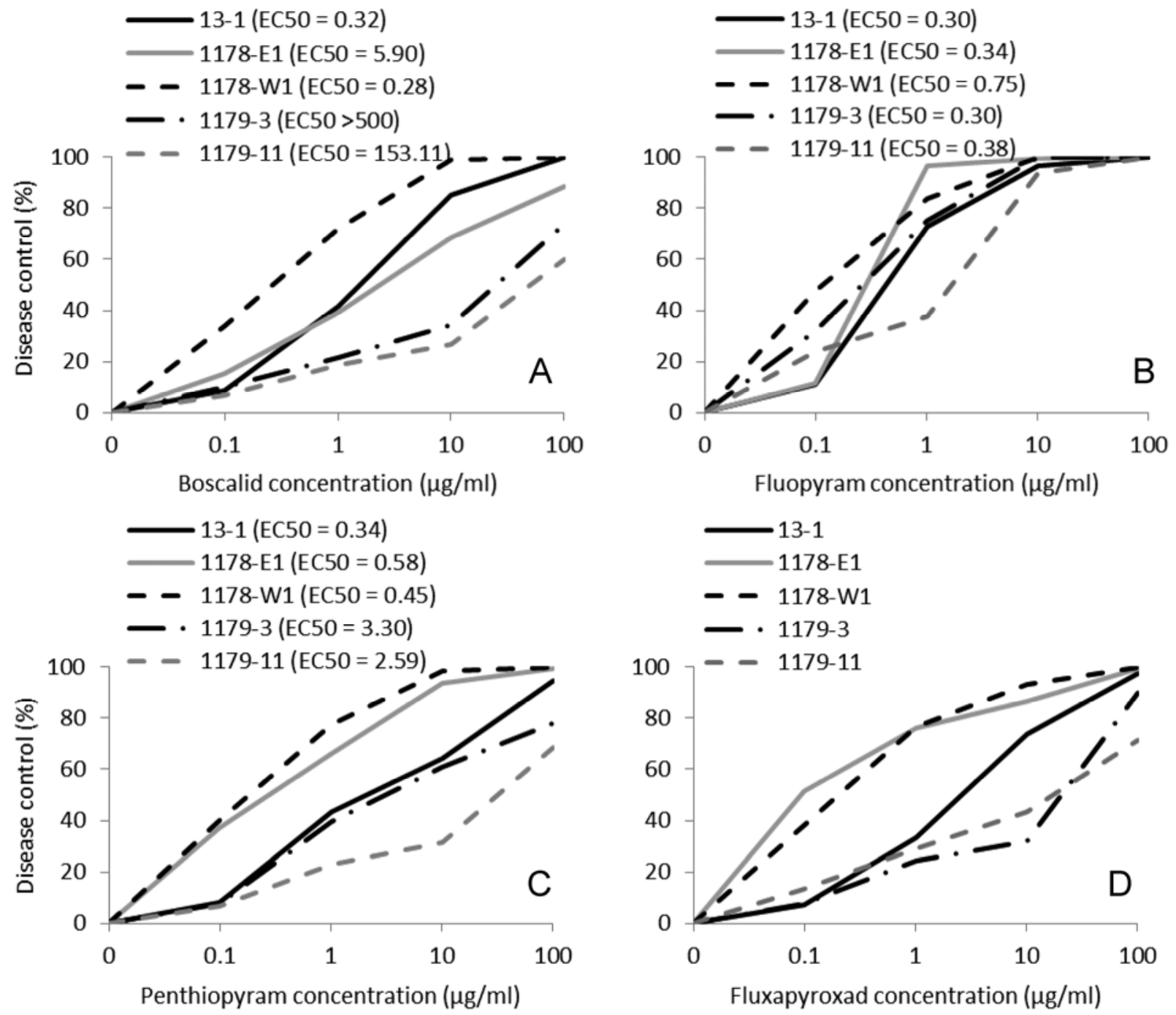

Fig. 6. In vivo percent disease control of Alternaria solani isolates by the succinate dehydrogenase inhibiting (SDHI) fungicides A, boscalid; $\mathbf{B}$, fluopyram; C, penthiopyrad; and $\mathbf{D}$, fluxapyroxad as determined in greenhouse assays. In vitro $\mathrm{EC}_{50}$ values were not determined for fluxapyroxad due to lack of availability of technical grade product.

Table 2. In vivo percent disease control of Alternaria solani isolates by succinate dehydrogenase inhibiting (SDHI) fungicides boscalid, penthiopyrad, fluopyram, and fluxapyroxad, as determined in greenhouse assays ${ }^{\mathrm{z}}$

\begin{tabular}{|c|c|c|c|c|c|c|c|c|c|c|}
\hline \multirow[b]{2}{*}{ Isolate } & \multirow{2}{*}{$\begin{array}{c}\text { In vitro } \\
\text { sensitivity } \\
(\mu \mathrm{g} / \mathrm{ml})\end{array}$} & \multicolumn{4}{|c|}{ Boscalid $(\mu \mathrm{g} / \mathrm{ml})$} & \multirow{2}{*}{$\begin{array}{c}\text { In vitro } \\
\text { sensitivity } \\
(\mu \mathrm{g} / \mathrm{ml})\end{array}$} & \multicolumn{4}{|c|}{ Fluopyram ( $\boldsymbol{\mu g} / \mathrm{ml})$} \\
\hline & & 0.1 & 1 & 10 & 100 & & 0.1 & 1 & 10 & 100 \\
\hline $13-1$ & 0.3 & $8.6 \mathrm{~b}$ & $41.3 \mathrm{~b}$ & $85.2 \mathrm{ab}$ & $100.0 \mathrm{a}$ & 0.3 & $11.1 \mathrm{c}$ & $73.0 \mathrm{~b}$ & $96.8 \mathrm{ab}$ & 100.0 \\
\hline 1178-E1 & 5.9 & $15.5 \mathrm{~b}$ & $39.0 \mathrm{bc}$ & $68.5 \mathrm{~b}$ & $88.4 \mathrm{~b}$ & 0.3 & $11.3 \mathrm{c}$ & $96.5 \mathrm{a}$ & $99.5 \mathrm{a}$ & 100.0 \\
\hline 1178-W1 & 0.3 & $33.9 \mathrm{a}$ & $71.7 \mathrm{a}$ & $99.1 \mathrm{a}$ & $100.0 \mathrm{a}$ & 0.8 & $47.6 \mathrm{a}$ & $84.0 \mathrm{ab}$ & $100.0 \mathrm{a}$ & 100.0 \\
\hline $1179-3$ & $>500$ & $10.3 \mathrm{~b}$ & $21.5 \mathrm{~cd}$ & $34.1 \mathrm{c}$ & $74.0 \mathrm{c}$ & 0.3 & $31.9 \mathrm{ab}$ & $75.0 \mathrm{~b}$ & $100.0 \mathrm{a}$ & 100.0 \\
\hline $1179-11$ & 153.1 & $6.8 \mathrm{~b}$ & $18.6 \mathrm{~d}$ & $26.6 \mathrm{c}$ & $59.9 \mathrm{~d}$ & 0.4 & $23.9 \mathrm{bc}$ & $37.5 \mathrm{c}$ & $93.8 \mathrm{~b}$ & 100.0 \\
\hline $\operatorname{LSD}_{P}=0.05$ & & 17.4 & 18.7 & 25.1 & 10.2 & & 19.7 & 21.5 & 4.3 & 0.0 \\
\hline
\end{tabular}

${ }^{\mathrm{z}}$ In vitro concentration that reduced germination by half $\left(\mathrm{EC}_{50}\right.$ value) was not determined for fluxapyroxad due to lack of availability of technical grade product. 
A. solani, regardless of the in vitro level of boscalid resistance, were also not controlled by fluxapyroxad except at the highest concentration of the fungicide. Although we could not determine the in vitro sensitivity of $A$. solani isolates to fluxapyroxad, we conclude from the in vivo experiments that boscalid resistant $A$. solani will possess cross-resistance to fluxapyroxad. As reported elsewhere (11), boscalid resistant isolates of A. solani were controlled by fluopyram as well as the wild-type isolates were controlled by this fungicide, although in Corynespora cassiicola, some isolates with moderate resistance to boscalid were not controlled as well as sensitive isolates. Fluopyram was registered in the United States in early 2012, and concomitant with the results reported in these studies, it provided excellent control of early blight in those regions where high levels of boscalid resistance in A. solani have been detected (N. C. Gudmestad, personal observation). However, given the ability of $A$. solani to develop resistance to boscalid and QoI fungicides, it is highly likely that resistance will also develop to fluopyram in the future.

QoI resistance in A. solani was detected in only 3 years after azoxystrobin was registered for use on potato (20). The development of QoI resistance was easily understood given the use patterns at the time. In nearly all instances where $A$. solani had developed resistance against azoxystrobin, it was documented that potato growers had used 12 to 15 applications of the fungicide over three growing seasons, which apparently put significant pressure on the pathogen population (20). However, the explanation for the development of boscalid resistance in the early blight pathogen is not so easily evident. In nearly all cases, potato growers involved in the survey conducted for these studies reported using only one or two applications of boscalid per growing season, in a 12 to 16 foliar fungicide regime, since 2005. In eastern Nebraska, two potato growers participated in these studies. One used only a single boscalid application on each field per growing season, whereas the other grower had used either one or two applications per season since boscalid was introduced, yet both farms had A. solani populations that were $100 \%$ resistant to the fungicide. Both growers also tank-mixed boscalid with a standard protectant fungicide such as mancozeb or chlorothalonil and also alternated boscalid with fungicide chemistry from another class in an effort to reduce the risk of resistance development. Interestingly, potato growers participating in these studies in western Nebraska have a nearly $100 \%$ boscalid sensitive population, probably due to slow adoption of this fungicide technology since boscalid was not used in this potato production region until 2008, 3 years after its introduction into the potato fungicide market. In contrast, in North Dakota it has been documented that one potato grower used a minimum of four boscalid applications per season in each field and used neither rotations nor tank-mixes with other fungicide chemistry. Nearly $100 \%$ of the early blight samples collected from within $10 \mathrm{~km}$ of this farm were determined to be resistant to boscalid. The development of resistance to boscalid in A. solani in Idaho is perhaps even more interesting given the relatively high incidence of moderately resistant isolates relative to other states. Boscalid has been used more than any other foliar fungicide in Idaho over the past few years ( $\mathrm{J}$. Miller, unpublished data). Some growers in Idaho have applied boscalid alone at the lower end of the rate range on multiple occasions in a single season. Manufacturer recommendations allowed for relatively lower use rates if the growers were using boscalid to manage early blight. Higher use rates were recommended if white mold was the target disease. Unfortunately, some Idaho producers have reported that boscalid was the only fungicide used for managing foliar diseases at times. The use of relatively low rates of boscalid and the lack of rotation may explain the development of resistance and moderate resistance in Idaho.

Nearly $99 \%$ of all of the A. solani isolates possessing some level of boscalid resistance also possess the F129L mutation in the cytochrome $\mathrm{b}$ gene. This means that nearly $80 \%$ of the A. solani population possesses dual fungicide resistance. In fact, we detected only one true wild-type isolate of $A$. solani over the course of this 2-year study. Previous studies with $A$. solani could not identify any obvious fitness penalty associated with QoI resistance (18). While the current displacement of $A$. solani wild-type isolates from the population strongly suggests that there is no fitness penalty associated with dual QoI and SDHI resistance, studies performed with $A$. alternata suggest that there may be some penalty, such as an increased sensitivity to oxidative stress (3). Since there are at least two phenotypes of boscalid resistance in A. solani, studies that evaluate pathogenic fitness of these isolates are warranted.

In plant pathogenic fungi, it has been suggested that multiple mutations in the SDH complex convey resistance to boscalid and that they are primarily present in the $s d h B$ gene, with the potential of other mutations that convey resistance present in the $s d h C$ or $s d h D$ genes (3). In A. alternata, there are two mutations in the Aasdh $\mathrm{B}$ gene sequence that convey a high level of resistance to boscalid $(3,5)$. The mutations convert the highly conserved histidine residue to either tyrosine (type I) or arginine (type II) at position 277. In D. bryoniae, boscalid resistance is also the result of mutations in the $D b s d h$ B protein, where histidine is substituted by either tyrosine or arginine (7). A similar situation exists with $B$. cinerea in which histidine is substituted at position 272 in the $B c s d h \mathrm{~B}$ protein and in $C$. cassiicola at position $278(15,25)$. Two other mutations in A. alternata convey resistance and are located in the $s d h C$ and $s d h D$ gene sequences (type III resistance) (6), which have also been implicated in conveying a moderate level of resistance to boscalid in $C$. cassiicola (15). Preliminary studies comparing $s d h A, s d h B, s d h C$, and $s d h D$ gene sequences from wild-type $A$. solani isolates to isolates displaying moderate or high resistance to boscalid have revealed single nucleotide polymorphisms in $s d h B, s d h C$, and $s d h D$ genes. The focus of future work will be to perform the necessary molecular characterization to elucidate the exact mechanisms of resistance and to develop molecular diagnostic methods to rapidly screen $A$. solani populations for boscalid resistance.

The research reported here clearly establishes that boscalid resistance is prevalent in many potato production regions of the United States. Results from these studies also demonstrate that there is a lack of complete cross-resistance among the SDHI fungicides boscalid, penthiopyrad, and fluopyram in A. solani. While this has been demonstrated also in previous studies $(3,7,11,23)$, to our knowledge this is the first report that clearly proves that there are differential sensitivities and a lack of cross-resistance to SDHI fungicides in a plant pathogenic fungus using multiple hypothesis driven methodologies. In the studies reported here, we demonstrate a lack of cross-resistance in A. solani to multiple SDHI fungicides

Table 2. (continued)

\begin{tabular}{|c|c|c|c|c|c|c|c|c|c|c|}
\hline \multirow[b]{2}{*}{ Isolate } & \multirow{2}{*}{$\begin{array}{c}\text { In vitro } \\
\text { sensitivity } \\
(\mu \mathrm{g} / \mathrm{ml})\end{array}$} & \multicolumn{4}{|c|}{ Penthiopyrad ( $\mu \mathrm{g} / \mathrm{ml})$} & \multirow{2}{*}{$\begin{array}{c}\text { In vitro } \\
\text { sensitivity } \\
(\mu \mathrm{g} / \mathrm{ml})\end{array}$} & \multicolumn{4}{|c|}{ Fluxapyroxad $(\mu \mathrm{g} / \mathrm{ml})$} \\
\hline & & 0.1 & 1 & 10 & 100 & & 0.1 & 1 & 10 & 100 \\
\hline $13-1$ & 0.3 & $8.2 \mathrm{~b}$ & $43.5 \mathrm{bc}$ & $64.4 \mathrm{~b}$ & $94.5 \mathrm{a}$ & NA & $7.1 \mathrm{~b}$ & $33.2 \mathrm{~b}$ & $74.0 \mathrm{a}$ & $97.4 \mathrm{a}$ \\
\hline 1178-E1 & 0.6 & $37.3 \mathrm{a}$ & $66.1 \mathrm{ab}$ & $93.9 \mathrm{a}$ & $99.4 \mathrm{a}$ & NA & $51.2 \mathrm{a}$ & $76.0 \mathrm{a}$ & $86.5 \mathrm{a}$ & $99.7 \mathrm{a}$ \\
\hline 1178-W1 & 0.5 & $40.2 \mathrm{a}$ & $77.6 \mathrm{a}$ & $98.6 \mathrm{a}$ & $100.0 \mathrm{a}$ & NA & $38.4 \mathrm{a}$ & $76.7 \mathrm{a}$ & $93.1 \mathrm{a}$ & $100.0 \mathrm{a}$ \\
\hline $1179-3$ & 3.3 & $7.7 \mathrm{~b}$ & $39.6 \mathrm{bc}$ & $61.0 \mathrm{~b}$ & $78.1 \mathrm{~b}$ & NA & $7.9 \mathrm{~b}$ & $24.2 \mathrm{~b}$ & $32.0 \mathrm{~b}$ & $89.9 \mathrm{~b}$ \\
\hline 1179-11 & 2.6 & $6.8 \mathrm{~b}$ & $23.0 \mathrm{c}$ & $31.4 \mathrm{c}$ & $68.7 \mathrm{c}$ & NA & $13.6 \mathrm{~b}$ & $29.3 \mathrm{~b}$ & $43.2 \mathrm{~b}$ & $71.4 \mathrm{c}$ \\
\hline $\mathrm{LSD}_{P}=0.05$ & & 14.5 & 29.8 & 17.2 & 6.7 & & 12.9 & 19.5 & 20.0 & 5.6 \\
\hline
\end{tabular}


using studies on in vitro baseline sensitivity, in vitro shifts in sensitivity, and in vivo disease control studies. We believe that a lack of cross-resistance among fungicides in the same chemical class can be conclusively demonstrated only by performing studies that investigate all three parameters.

\section{Acknowledgments}

Technical support was provided by Ipsita Mallik, Roberta Sherman, Nolan Anderson, Dean Peterson, and Russell Benz. Financial support from DuPont and Bayer CropScience is gratefully acknowledged.

\section{Literature Cited}

1. Amiri, A., Brannen, P. M., and Schnabel, G. 2010. Reduced sensitivity in Monilinia fructicola field isolates from South Carolina and Georgia to respiration inhibitor fungicides. Plant Dis. 94:737-743.

2. Avenot, H. F., and Michailides, T. J. 2007. Resistance to boscalid fungicide in Alternaria alternata isolates from pistachio in California. Plant Dis. 91:1345-1350.

3. Avenot, H. F., and Michailides, T. J. 2010. Progress in understanding molecular mechanisms and evolution of resistance to succinate dehydrogenase inhibiting (SDHI) fungicides in phytopathogenic fungi. Crop Prot. 29:643-651.

4. Avenot, H. F., Morgan, D. P., and Michailides, T. J. 2008. Resistance to pyraclostrobin, boscalid and multiple resistance to Pristine ${ }^{\circledR}$ (pyraclostrobin + boscalid) fungicide in Alternaria alternata causing alternaria late blight of pistachios in California. Plant Pathol. 57:135-140.

5. Avenot, H. F., Sellam, A., Karaoglanidis, G., and Michailides, T. J. 2008. Characterization of mutations in the iron-sulphur subunit of succinate dehydrogenase correlating with boscalid resistance in Alternaria alternata from California pistachio. Phytopathology 98:736-742.

6. Avenot, H. F., Sellam, A., and Michailides, T. J. 2009. Characterization of mutations in the membrane-anchored subunits of AaSDHC and AaSDHD of succinate dehydrogenase from Alternaria alternata isolates conferring field resistance to the fungicide boscalid. Plant Pathol. 58:1134-1143.

7. Avenot, H. F., Thomas, A., Gitaitis, R. D., Langston, D. B., Jr., and Stevenson, K. 2012. Molecular characterization of boscalid- and penthiopyrad-resistant isolates of Didymella bryoniae and assessment of their sensitivity to fluopyram. Pest Manag. Sci. 68:645-651.

8. Bardas, G. A., Veloukas, T., Koutita, O., and Karaoglanidis, G. S. 2010. Multiple resistance of Botrytis cinerea from kiwifruit to SDHIs, QoIs and fungicides of other chemical groups. Pest Manag. Sci. 66:967-973.

9. Franc, G. D., and Christ, B. J. 2001. Early blight. Pages 22-23 in: Compendium of Potato Diseases. W. R. Stevenson, Loria, R., Franc, G. D., and Weingartner, G. D., eds. American Phytopathological Society, St. Paul, MN.

10. Holm, A. L., Rivera, V. V., Secor, G. A., and Gudmestad, N. C. 2003. Temporal sensitivity of Alternaria solani to foliar fungicides. Am. J. Potato Res. 80:33-40.

11. Ishii, H., Miyamoto, T., Ushio, S., and Kakishima, M. 2011. Lack of cross- resistance to a novel succinate dehydrogenase inhibitor, fluopyram, in highly boscalid-resistant isolates of Corynespora cassiicola and Podosphaera xanthii. Pest Manag. Sci. 67:474-482.

12. Leroch, M., Kretschmer, M., and Hahn, M. 2011. Fungicide resistance phenotypes of Botrytis cinerea isolates from commercial vineyards in South West Germany. J. Phytopathol. 159:63-65.

13. Milliken, G. A., and Johnson, D. E. 1992. One-way treatment structure in a completely randomized design with heterogeneous errors. Pages 16-28 in: Analysis of Messy Data. Vol. I: Designed Experiments. Chapman and Hall, London.

14. Miyamoto, T., Ishii, H., Seko, T., Kobori, S., and Tomita, Y. 2009. Occurrence of Corynespora cassiicola isolates resistant to boscalid on cucumber in Ibaraki Prefecture, Japan. Plant Pathol. 58:1144-1151.

15. Miyamoto, T., Ishii, H., Stammler, G., Koch, A., Ogawara, T., Tomita, Y., Fountaine, J. M., Ushio, S., Seko, T., and Kobori, S. 2010. Distribution and molecular characterization of Corynespora cassiicola isolates resistant to boscalid. Plant Pathol. 59:873-881.

16. Miyamoto, T., Ishii, H., and Tomita, Y. 2010. Occurrence of boscalid resistance in cucumber powdery mildew in Japan and molecular characterization of the iron-sulfur protein of succinate dehydrogenase of the causal fungus. J. Gen. Plant Pathol. 76:261-267.

17. Myresiotis, C. K., Bardas, G. A., and Karaglanidis, G. S. 2008. Baseline sensitivity of Botrytis cinerea to pyraclostrobin and boscalid and control of anilinopyrimdine- and benzimidazole-resistant strains by these fungicides. Plant Dis. 92:1427-1431.

18. Pasche, J. S., and Gudmestad, N. C. 2008. Prevalence, competitive fitness and impact of the F129L mutation in Alternaria solani in the United States. Crop Prot. 27:427-435.

19. Pasche, J. S., Piche, L. M., and Gudmestad, N. C. 2005. Effect of the F129L mutation in Alternaria solani on fungicides affecting mitochondrial respiration. Plant Dis. 89:269-278.

20. Pasche, J. S., Wharam, C., and Gudmestad, N. C. 2004. Shift in sensitivity of Alternaria solani in response to QoI fungicides. Plant Dis. 88:181-187.

21. Stammler, G., Brix, H. D., Glattli, A., Semar, M., and Schoefl, U. 2007. Biological properties of the carboxamide boscalid including recent studies on its mode of action. Pages 40-45 in: Proc. XVI Int. Plant Prot. Congr., Glascow.

22. Stevenson, W. R., and James, R. V. 1999. Evaluation of fungicides to control early blight and late blight of potato-Hancock, 1998. Fungic. Nematicide Tests 54:212-213.

23. Thomas, A., Langston, D. B., Jr., and Stevenson, K. L. 2012. Baseline sensitivity and cross-resistance to succinate-dehydrogenase-inhibiting and demethylation-inhibiting fungicides in Didymella bryoniae. Plant Dis. 96:979-984.

24. Wharton, P., Fairchild, K., Belcher, A., and Wood, E. 2012. First report of in-vitro boscalid-resistant isolates of Alternaria solani causing early blight of potato in Idaho. Plant Dis. 96:454.

25. Yin, Y. N., Kim, Y. K., and Xiao, C. L. 2011. Molecular characterization of boscalid resistance in field isolates of Botrytis cinerea from apple. Phytopathology 101:986-995 